\title{
Electron Microscopy of Salmonella Flagella in Methylcellulose Solution
}

\author{
BY MICHIKO MITANI* AND T. IINO \\ National Institute of Genetics, Misima, Japan
}

(Accepted for publication 24 August 1967)

\begin{abstract}
SUMMARY
When peritrichously flagellated cells such as normal, curly, paralysedcurly and small-amplitude strains of Salmonella abortusequi are suspended in $0.5 \%$ methylcellulose solution, flagellar bundles can be clearly seen by electron microscopy. In a bundle, five or more of the component flagella are tightly united in parallel with each other, and the bundle formed into a helix with a shape characteristic for each strain. These figures reveal the structural detail of the flagellar bundle observed under a dark-field microscope. Ten minutes after the cells were suspended in methylcellulose solution, bundled flagella could be seen in approximately $70 \%$ of the cells of normal, curly and paralysed-curly strains; the remaining $30 \%$ were dispersed. At this time among the normal cells, some were single-bundled and others were multibundled. The fraction of single-bundled cells was larger in both motile and paralysed curly-flagellated cells than in normal cells. The fraction of normal cells having single bundles increased with time. Methylcellulose was therefore presumed to enhance aggregation of flagella and/or to inhibit the dispersion of the aggregated flagella.

In the small-amplitude strain, transformation of flagellar shape to curly has been previously observed. In methylcellulose solution, this transformation occurs in bundled flagella but not in dispersed flagella. It is inferred that the tight association of the component flagella in methylcellulose solution enhances the stress among the flagella, thus causing the transformation.
\end{abstract}

\section{INTRODUCTION}

Pijper (1957), using dark-field microscopy, was able to observe bundled flagella in moving bacteria. They can also be observed by electron microscopy (Mitani \& Iino, I965), although with more difficulty, especially in the case of normal flagella. Pijper \& Abraham (1954) report that suspension of bacteria in colloidal substances such as agar, gum arabic and methylcellulose facilitates the observation of bundled flagella by dark-field microscopy. Suspension of bacteria in methylcellulose has proved equally useful for electron microscopy. The present paper describes our observations of flagella in normal cells as well as in derived mutant strains. Observations of the transformation of shape of bundled flagella from small-amplitude to curly previously made by dark-field light microscopy (Iino \& Mitani, 1966) were repeated by electron microscopy.

* Present address: Division of Biology, Southwest Center for Advanced Studies, Dallas, Texas, U.S.A. 


\section{METHODS}

The strains used in the present observations were Salmonella abortusequi SL 23, which has peritrichous normal flagella, and the derived mutants $\mathrm{SJ} 30, \mathrm{sJ} 706$ and SJ $7 \mathrm{I} 2$. SJ 30 has curly flagella; this is thought to be due to a mutation of the structural gene for flagellin of SL 23 (Iino, I962). SJ 706 is a paralysed-curly strain found as a mutation of a motility gene for SJ 30 (Mitani \& Iino, I965). SJ 7 I 2 is a small-amplitude mutant from SJ 30 , in which transformation of flagella from small-amplitude to curly was observed by dark-field microscopy (Iino \& Mitani, I966).

The medium for the cultivation of bacteria consisted of $(\mathrm{w} / \mathrm{v}) 0.15 \%$ beef extract (Difco), $0.15 \%$ yeast extract (Difco), $0.5 \%$ Kyokuto peptone, $0.1 \%$ glucose, $0.35 \%$ $\mathrm{NaCl}, 0.36 \% \mathrm{~K}_{2} \mathrm{HPO}_{4}$, and $0.32 \% \mathrm{KH}_{2} \mathrm{PO}_{4}$. Cells cultivated overnight at $37^{\circ}$ without shaking, inoculated into $10 \mathrm{ml}$. of the medium and incubated for $2 \mathrm{hr}$ with aeration at $37^{\circ}$, were used for microscopy unless otherwise stated.

For electron microscopy, cells were harvested by centrifugation at $1200 \mathrm{~g}$ for 15 min., and resuspended in a solution containing equal volumes of $2 \%(\mathrm{w} / \mathrm{v})$ potassium phosphotungstate and $0.5 \%(\mathrm{w} / \mathrm{v})$ methylcellulose, $\mathrm{pH} 7.0$. As a control, centrifuged cells were resuspended in I \% (w/v) solution of potassium phosphotungstate. Motility was retained for at least 180 min. in these suspensions. Small drops of the suspension were then placed on collodion supporting films at the intervals described in each experiment and dried immediately with a vacuum pump. The electron microscope used was a JEM T6S (Japan Electron Optics Laboratory Co., Ltd.), with a single condenser system and accelerating voltage of $60 \mathrm{kV}$.

Electron micrographs were taken at an initial magnification of $\times 5000$ on Sakura hard process plates. One-micron Bacto-latex particles (Difco Lab., Inc., Detroit, Michigan, U.S.A.) were photographed at the same magnification in order to determine the final magnification. To measure the spiral unit length of waves in flagella, the micrographs were projected and several waves measured in a single flagellum or a flagellar bundle on different organisms; in total 50 to 80 waves were examined per clone.

Dark-field microscopy was done by the procedure of Iino \& Mitani (1966).

\section{RESULTS}

\section{Bundled flagella in methylcellulose solution}

Plates I and 2 show electron micrographs of flagellar bundles of normal, curly and paralysed-curly cells suspended in methylcellulose solution. The bundled flagella were more tightly aggregated in the presence of methylcellulose than in its absence (cf. Fig. 3, Mitani \& Iino, 1965). The proportion of the cells with bundled flagella in each bacterial culture did not differ significantly among the three strains, even in motile and paralysed ones; approximately $70 \%$ of the flagellated cells were bundled and the remaining $30 \%$ were dispersed (Table I). Among the cells with bundled flagella, some were single-bundled, i.e. all flagella of a cell had united to form a bundle, and others were multi-bundled, i.e. more than two flagellar bundles were formed per cell. The fraction of single-bundled cells was substantially larger in both curly $(65 \%)$ and paralysed-curly cells $(57 \%)$ than in normal cells ( $15 \%$ ).

The observation of normal cells at Io and I 80 min. after the cells had been sus- 
pended in methylcellulose solution showed that the fraction of dispersed flagella did not change during this interval, but there was an increase of single-bundled cells at the expense of multi-bundled cells (Table 2). Further observations over shorter intervals indicated that the proportion of single-bundled increased between Io and $30 \mathrm{~min}$. after suspending of the cells in methylcellulose; after $30 \mathrm{~min}$. the ratio between singleand multi-bundled cells changed little.

Table I. The relative frequency of bundled and dispersed flagella observed in normal, curly and paralysed-curly strains of Salmonella abortusequi suspended for ro min. in $0.5 \%(w / v)$ methylcellulose solution.

\begin{tabular}{|c|c|c|c|c|c|c|c|}
\hline \multirow[b]{2}{*}{ Strain } & \multirow{2}{*}{$\begin{array}{c}\text { Cells } \\
\text { observed }\end{array}$} & \multirow{2}{*}{$\begin{array}{c}\text { Flagella- } \\
\text { tion } \\
(\%)\end{array}$} & \multicolumn{2}{|c|}{$\begin{array}{l}\begin{array}{c}\text { Flagellated } \\
\text { cells }(\%)\end{array} \\
.\end{array}$} & \multicolumn{2}{|c|}{$\begin{array}{c}\text { Bundle flagellated } \\
\text { cells }(\%)\end{array}$} & \multirow{2}{*}{$\begin{array}{l}\text { Average no. of } \\
\text { flagella/cell }\end{array}$} \\
\hline & & & Bundle & Dispersed & Single & Multiple & \\
\hline SL 23 (normal) & 100 & 97 & 68 & 32 & 15 & 85 & $9 \cdot 5 \pm I \cdot 2^{*}$ \\
\hline SJ 30 (curly) & 129 & 57 & 70 & 30 & 65 & 35 & $10 \cdot 7 \pm 2 \cdot 6$ \\
\hline SJ 706 (paralysed-curly) & I3I & 54 & 69 & $3 \mathrm{I}$ & 57 & 43 & $6 \cdot 4 \pm 1 \cdot 4$ \\
\hline
\end{tabular}

Table 2. Change in the proportion of multi-and single-bundled types among bundled flagella of normal strain SL23 with time in methylcellulose solution

$\begin{array}{ccccc}\begin{array}{c}\text { Time in } \\ \text { methylcellulose } \\ \text { solution (min.) }\end{array} & \begin{array}{c}\text { Cells } \\ \text { observed }\end{array} & \text { Single } & \text { Multiple } & \begin{array}{c}\text { Bundle flagellated cells (\%) } \\ \text { flagellated } \\ \text { cells) }\end{array} \\ \text { O } & \text { I05 } & 0 & 0 & \text { I00 } \\ \text { I0 } & 100 & 15 & 85 & 32 \\ \text { I80 } & 106 & 33 & 67 & 34\end{array}$

Transformation of the shape of bundled flagella in small-amplitude strain SF7I2

The wavelength, amplitude and helical unit length, which is defined as a contour length of one wave of flagellar bundle, were comparable in strains SL 23, SJ 30 and SJ 706 to those of dispersed flagella and did not change during the period of observation. On the other hand, if strain SJ 712 was suspended in $0.5 \%$ methylcellulose solution, in the bundled flagella a transformation of curvature from small-amplitude to curly occurred. Dark-field photomicrographs of this transformation of flagellar bundles are shown in P1. 3, where it can be seen that the transition is initiated at the distal end of the flagellar bundle and proceeds proximally to its base. On this organism, one helical unit of the small-amplitude transformed to curly in approximately $45 \mathrm{~min}$. Continuous observation showed that the transformed part had twirled around the axis of the original flagellar bundle. An overnight culture of $\mathrm{sJ} 7 \mathrm{I} 2$ was examined in the dark-field microscope $80 \mathrm{~min}$. after suspension of the cells in $0.5 \%$ methylcellulose solution. The fractions of the cells with small-amplitude, curly and dimorphously bundled flagella of the former two flagellar shapes were 59, 36 and $5 \%$ respectively. But when the cell had been previously fixed with $0.5 \%$ formalin the transformation was never observed.

The morphological change of the flagella of this strain had not previously been observed electron-microscopically on preparations stained with $2 \%$ potassium phos- 
photungstate (Iino \& Mitani, 1966). The reason was made clear when the solution of $0.5 \%$ methylcellulose in which the small-amplitude strain was suspended was dropped on a grid, and the preparation was observed in the electron microscope. Two morphologically different types of flagellar bundles, one shorter and the other longer, were identified (Pl. 4). In methylcellulose, some of the cells of this strain also formed flagellar bundles and the rest dispersed, as has been shown for the other strains. The longer the exposure to methylcellulose was, the larger the number of cells with bundled flagella of shorter helical unit length. Three hundred minutes after the cells had been suspended in methylcellulose the flagellar bundles were examined by electronmicroscope and photographed; and their helical unit length was measured. As a control, the flagellar bundle of the cells kept for $10 \mathrm{~min}$. in methylcellulose was observed. The distribution diagrams of the helical unit length of the flagellar bundle of these two samples indicated that the fraction of shorter helical unit length was increased 12 times

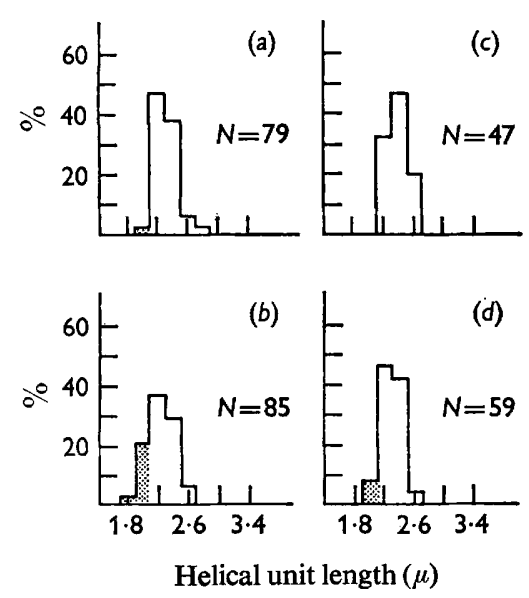

Fig. I

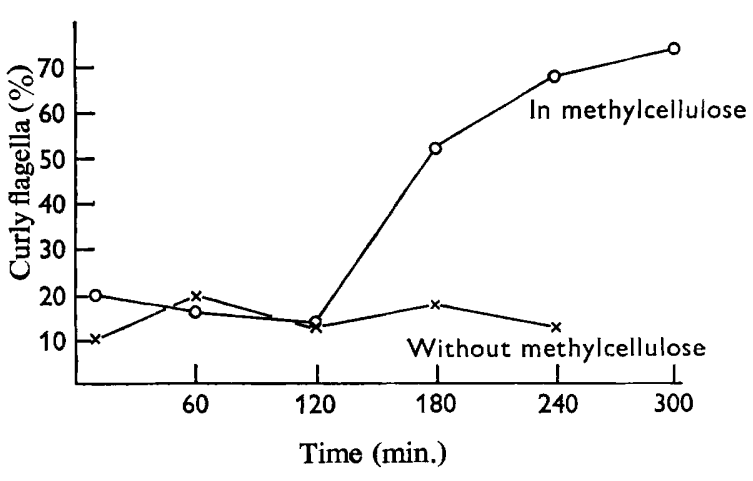

Fig. 2

Fig. I. Distribution diagram of helical unit length of flagella in Salmonella SJ 712: bundled flagella (a) 10 min., (b) $300 \mathrm{~min}$., and dispersed flagella (c) 10 min., (d) $300 \mathrm{~min}$. after the bacteria had been suspended in methylcellulose solution. $N$ denotes the number of flagellar waves observed. Dotted parts show the fraction of the bacteria with shorter helical unit length.

Fig. 2. Transformation of bundled flagella from small-amplitude to curly in Salmonella SJ 7 I 2 as observed by electron microscopy: $O$, with methylcellulose; $\times$, without methylcellulose. Number of bacteria observed at each time interval varied from 92 to I 16.

in the preparation which remained $300 \mathrm{~min}$. in methylcellulose (Fig. $1 a, b$ ). Further timed experiments indicated that the cell fraction with the short wavelength flagella started to increase $120 \mathrm{~min}$. after the cells had been suspended in methylcellulose solution (Fig. 2).

From these results, it was inferred that the longer helical unit type corresponded to the small-amplitude type, and the shorter to the curly type observed by dark-field microscopy. The increase in the proportion of organisms of shorter helical unit length was taken as a manifestation of the transformation of the flagellar bundle as demonstrated by electron microscopy. However, this experiment alone did not allow a decision as to whether the effect of methylcellulose on the transformation was on the 
individual flagella or on the flagella when bundled. Therefore the helical unit lengths of the dispersed flagella on the preparations kept both 10 and $300 \mathrm{~min}$. in methylcellulose solution were measured. The change of the helical unit length was very slight even though the cells were suspended for $300 \mathrm{~min}$. in that solution (Fig. I $c, d$ ). The observations are interpreted to mean that the transformation of the flagella of this strain is promoted in methylcellulose solution on flagellar bundles but not on individual flagella. Although dimorphous flagellar bundles have been seen by dark-field light microscopy they have not hitherto been examined in the electron microscope. Furthermore, the distribution pattern of Fig. I is much sharper than that without methylcellulose (cf. Fig. 3 of lino \& Mitani, 1966).

\section{DISCUSSION}

In an earlier paper (Mitani \& Iino, 1965), bundles of peritrichous flagella were demonstrated electron-microscopically on a Salmonella strain with curly flagella. Bundles were also observed on a normal strain, but much less frequently than on the curly strain, and the observed bundles were rather loose and irregular. The present investigation shows that when the organisms are suspended in methylcellulose solution, flagellar bundles are clearly seen in the electron microscope in flagellated strains of various morphological types, including normal, curly and small-amplitude. In a bundle, five or more of the component flagella arrange themselves parallel to each other, and the bundle gyrates helically with the characteristic wave. Within the bundled flagella of cells suspended in methylcellulose solution the component flagella are more tightly and regularly aggregated than in samples prepared without methylcellulose. Methylcellulose may be effective in bringing about the tight combination of component flagella in a bundle to each other and preserving the bundle during specimen preparation for electron microscopy.

The increase of single-bundled cells in methylcellulose solution with time may support the idea that in methylcellulose solution aggregation of flagella is enhanced and/or the dispersion of the aggregated flagella is inhibited (Stocker, 1956). This may be true even if the cells are non-motile; on the paralysed-curly strain, it was shown that the fraction of bundled flagella in methylcellulose was considerably larger than that without methylcellulose (cf. Table I of this paper and table I of Mitani \& Iino, I965).

For the observation of flagella the methylcellulose treatment has an additional advantage: it is effective in preserving the regular flagellar waves during the process of drying for electron-microscopical observation. It is noticeable when Fig. I of this report is compared with Fig. 2 of Iino \& Mitani, (I966) that the scatter of helical unit length is narrower when measured on the samples suspended in methyl-cellulose solution. The difference in the dark-field and electron microscope on the cells of strain SJ7I 2 suspended in methylcellulose suggests that certain types of flagella have a tendency to stretch and flatten even in the presence of methylcellulose.

As for the transformation of flagellar shape from small-amplitude to curly in a mutant Salmonella strain, SJ712, this occurred on bundled flagella when they were suspended in methylcellulose solution but not on dispersed ones. When methylcellulose is absent bundled flagella are presumed not to be transformed. The stress brought about in the component flagella by their tight association in a bundle may cause the transformation. 
Contribution from the National Institute of Genetics, Misima, Japan, no. 65. This investigation was supported by Public Health Service Research Grant AI-02872 from the National Institute of Allergy and Infectious Diseases, U.S.A., and by a grant from the Toyo Rayon Foundation for the Promotion of Science and Technology. We would like to thank Mrs Kay Petty for typing this paper.

\section{REFERENCES}

IINO, T. (I962). Curly flagellar mutants in Salmonella. J. gen. Microbiol. 27, I62. Ino, T. \& Mitani, M. (I966). Flagella-shape mutants in Salmonella. J. gen. Microbiol. 44, 27.

Mitani, M. \& IINo, T. (1965). Electron microscopy of bundled flagella of the curly mutant of Salmonella abortivoequina. J. Bact. 90, 1096.

PiJPER, A. (1957). Bacterial flagella and motility. Ergebn. Mikrobiol. ImmunForsch. exp. Ther. 3o, 37.

Pijper, A. \& Abraham, G. (1954). Wavelength of bacterial flagella. J. gen. Microbiol. ro, 452.

STOcker, B. A. D. (1956). Bacterial flagella: morphology, constitution and inheritance. Symp. Soc. gen. Microbiol. 6, 19.

\section{EXPLANATION OF PLATES}

\section{Plate I}

Fig. I. Dispersed normal flagella of Salmonella abortusequi SL 23. The cells had been suspended in distilled water $(\mathrm{pH} \mathrm{6.8)}$ and were negatively stained with potassium phosphotungstate $(\mathrm{pH} 7 \cdot 0)$ for Io $\mathrm{min} . \times 14,400$.

Fig. 2. Bundled flagella of sL $23,300 \mathrm{~min}$. after the cells had been suspended in a mixture of potassium phosphotungstate and methylcellulose. $\times 14,400$.

Fig. 3. Dispersed flagella of SL 23 seen 300 min. after the cells had been suspended in a mixture of potassium phosphotungstate and methylcellulose. $\times 14,400$.

\section{Plate 2}

Fig. 4. Bundled flagella of curly strain sJ 30 , Io min. after the cells had been suspended in a mixture of potassium phosphotungstate and methylcellulose. $\times$ I 4,400 .

Fig. 5. Bundled flagella of paralysed-curly strain sJ 706, $90 \mathrm{~min}$. after the cells had been suspended in a mixture of potassium phosphotungstate and methylcellulose. $\times 14,400$.

\section{Plate 3}

Progressive transformation of bundled flagella from small-amplitude to curly in SJ 7I 2 as seen by dark-field microscopy, $90 \mathrm{~min}$. (fig. 6), I $20 \mathrm{~min}$. (fig. 7), $135 \mathrm{~min}$. (fig. 8) and $16.5 \mathrm{hr}$ (fig. 9) after the cells had been suspended in methylcellulose solution. $\times 3200$.

\section{Plate 4}

Fig. IO. Dispersed flagella of small-amplitude strain SJ 712. The cells had been suspended in distilled water $(\mathrm{pH} 6 \cdot 8)$ and were negatively stained by potassium phosphotungstate $(\mathrm{pH} 7 \cdot 0$ ) for 10 min. $\times 14,400$.

Fig. I I. Long helical unit length of bundled flagella of sJ 712, 10 min. after the cells had been suspended in a mixture of potassium phosphotungstate and methylcellulose. $\times 14,400$.

Fig. 12. Shorter helical unit length of bundled flagella of SJ 712, $300 \mathrm{~min}$. after the cells had been suspended in a mixture of potassium phosphotungstate and methylcellulose. $\times 14,400$. 
Journal of General Microbiology, Vol. 50, No. 3

Plate I
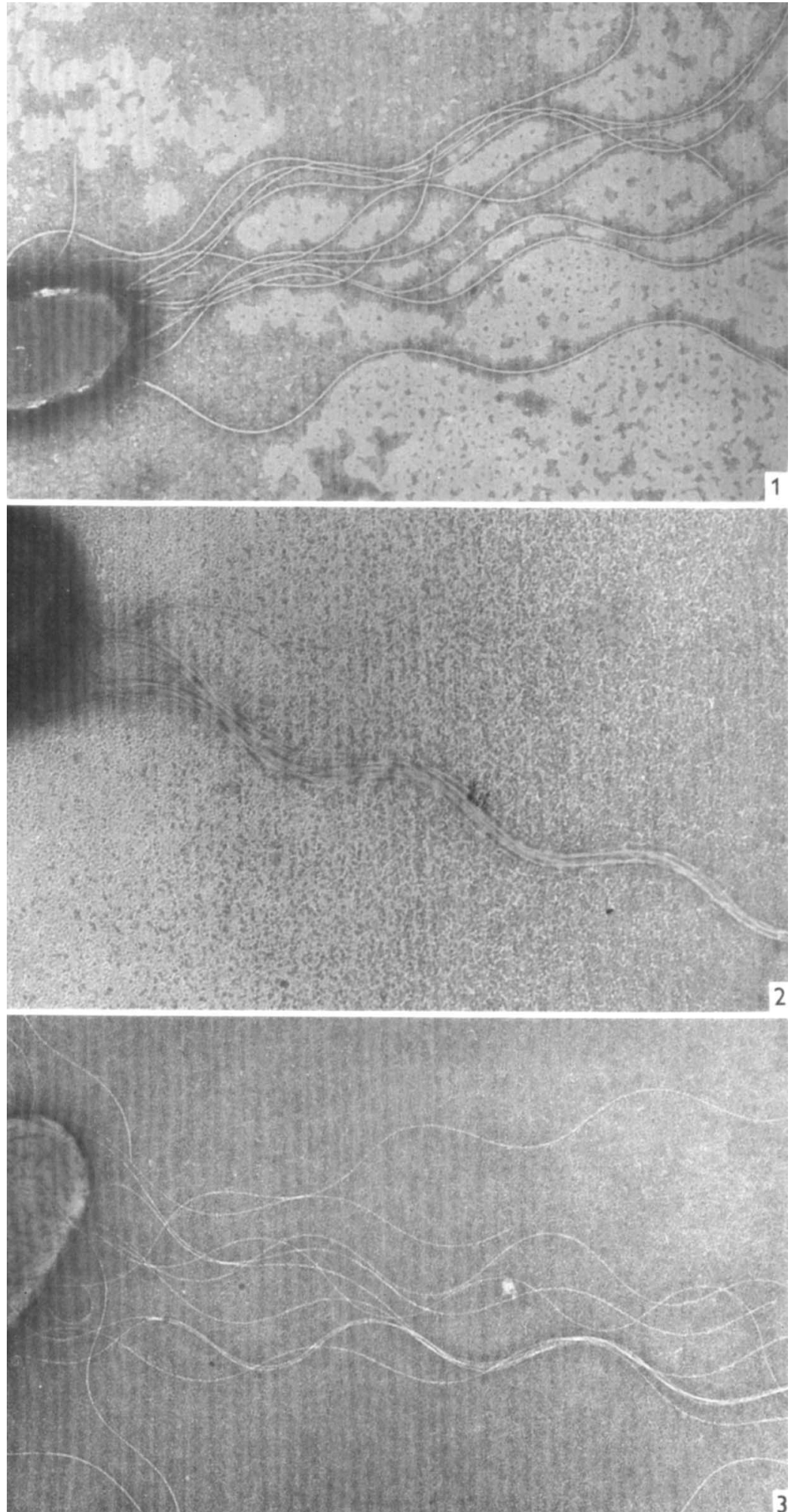
Journal of General Microbiology, Vol. 50, No. 3

Plate 2
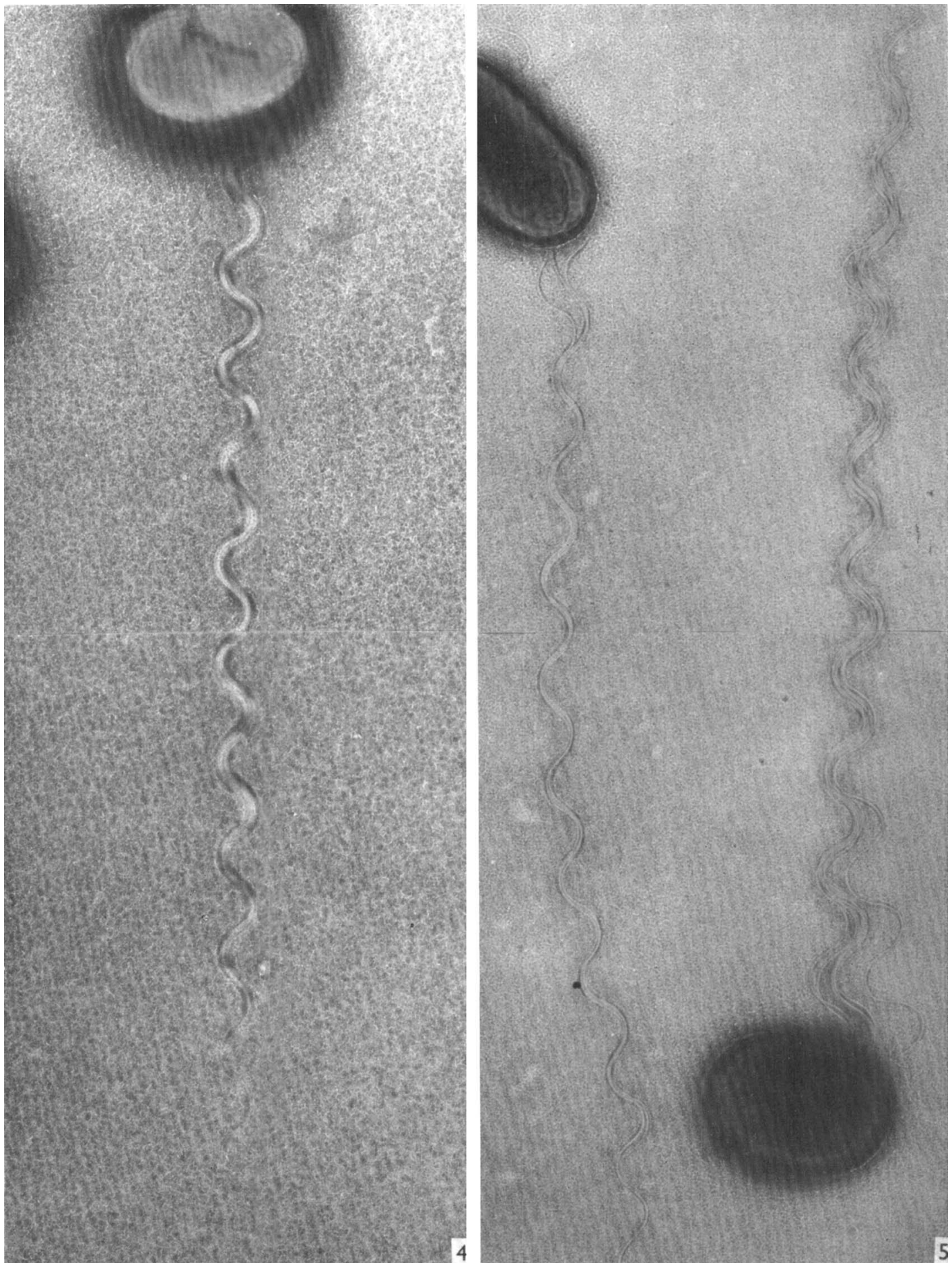

M. MITANI AND T. IINO 
Journal of General Microbiology, Vol. 50, No. 3

Plate 3
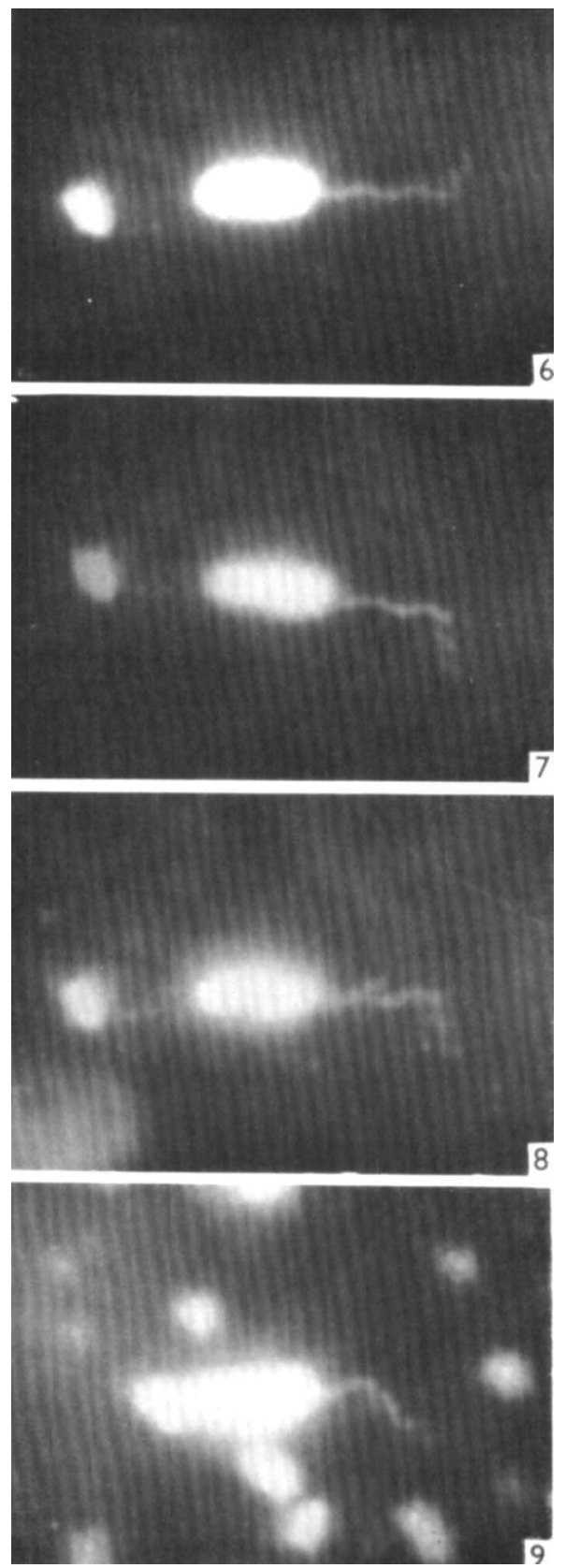

M. MITANI AND T. IINO 
Journal of General Microbiology, Vol. 50, No. 3

Plate 4
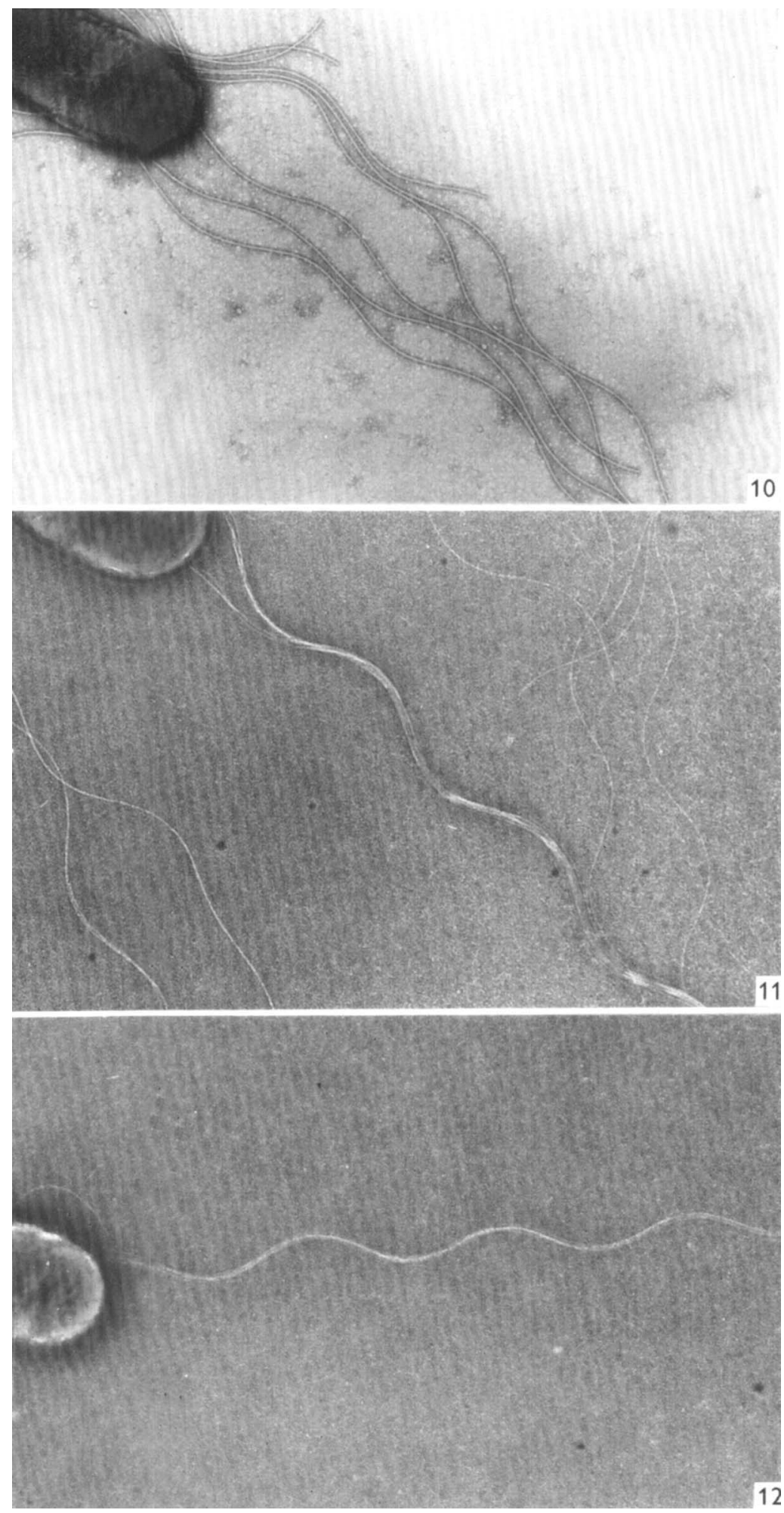

M. MITANI AND T. IINO 